\title{
Effects of male mating frequency and male size on ejaculate size and reproductive success of female spiny king crab Paralithodes brevipes
}

\author{
Taku Sato $^{1, *}$, Masakazu Ashidate ${ }^{2,3}$, Satoshi Wada ${ }^{1,4}$, Seiji Goshima1 \\ ${ }^{1}$ Laboratory of Marine Biodiversity, Graduate School of Fisheries Sciences, Hokkaido University, Hakodate, \\ Hokkaido 041-8611, Japan
}

${ }^{2}$ IAA, FRA, National Center for Stock Enhancement, Akkeshi Station, 2-1 Tsukushikoi, Akkeshi, Hokkaido 088-1160, Japan

${ }^{3}$ Present address: Incorporated Administrative Agency, Fisheries Research Agency, National Center for Stock Enhancement, Tamano Station, Chikkou, Tamano, Okayama 706-0002, Japan

${ }^{4}$ Present address: Laboratory of Invertebrate Biology, Usa Marine Biological Institute, Kochi University, Usa, Tosa, Kochi 781-1164, Japan

\begin{abstract}
Potential sperm limitation in a fished population of the spiny king crab Paralithodes brevipes was investigated in controlled laboratory experimental and field studies. The laboratory experiments examined the effects of male size and mating frequency on their reproductive potential and the recovery rate of exhausted sperm. The spawning success and fertilization rate of females decreased as the male mating frequency increased. The effects of increased male mating frequency on the spawning success of females and fertilization rates differed between male size classes. Male size and mating frequency have great influences on sperm limitation. Males showed little capacity to regenerate sperm, increasing the likelihood of limited sperm supply to females in fished population with low numbers of males due to male-selective fishing regulations. The field studies examined the structure of a fished population of $P$. brevipes in Hamanaka, eastern Hokkaido, before and after a change in the fishery regulations that permitted smaller males to be harvested. The results showed that a change in the sex ratio occurred after the fishery regulations were introduced, skewing the population towards females. The results also showed a decrease in the mean male size in the fished population. The results also indicated that a significant percentage of males (42.2\%) had depleted sperm reserves just after the reproductive season. Overall, the results indicate that sperm limitation could occur in this fished population of $P$. brevipes. These observations may warrant a review of the current fishing regulations, particularly the minimum legal size.
\end{abstract}

KEY WORDS: Sperm limitation - Male mating frequency $\cdot$ Male size $\cdot$ Reproductive potential • Recovery rate Resale or republication not permitted without written consent of the publisher

\section{INTRODUCTION}

Sperm production is costly and slow (Dewsbury 1982), and evidence exists that males do not always have sufficient sperm to fertilize all eggs spawned by a female (Nakatsuru \& Kramer 1982, Gage \& Cook 1994, Pitnick \& Markow 1994, Preston et al. 2001). Insufficient sperm supply can limit the reproductive success of females; that is, sperm limitation can occur (Royer \&
McNeil 1993, Svensson et al. 1998, Rondeau \& SainteMarie 2001). Recent studies have suggested that male mating frequency and male size are the main factors that induce females to receive a limited sperm supply from their mates. For example, as males deplete their sperm reserves after successive matings (Dewsbury 1982, Rutowski et al. 1987, Birkhead 1991, Pitnick \& Markow 1994, Bissoondath \& Wiklund 1996, Kendall et al. 2002), females that mate with these males later in 
the reproductive season receive fewer sperm. Small males limit the fertility of females by providing fewer sperm to the females (Powell et al. 1974, Bissoondath \& Wiklund 1996, MacDiarmid \& Bulter 1999). Therefore, the possibility that females suffer from insufficient sperm supply would be closely related to their population structure.

Several studies have investigated the possibility of sperm limitation in commercially fished decapod populations (e.g. Smith \& Jamieson 1991, Sainte-Marie \& Hazel 1992, Hankin et al. 1997, Paul \& Paul 1997, Rondeau \& Sainte-Marie 2001, Kendall et al. 2002), because only large males are selectively harvested in many large decapod crustacean fisheries. This regulation can skew the sex ratio toward females and decrease the mean male size in the population (Paul \& Adams 1984, Ennis et al. 1988, Abbe \& Stagg 1996). As a result, small mature males in the fished population replace large males in reproductive activity (Ennis et al. 1988, 1990, Sainte-Marie 1993) and mate more often than in the non-fished populations (Powell et al. 1974, Ennis et al. 1988, 1990, Sainte-Marie 1993). Recent studies in some large decapods have also suggested that male size and male mating frequency cause females to be limited in sperm supply. For example, compared with small males, large males retain more sperm reserves (Powell et al. 1974, Kwei 1978, Jivoff 1997, Kendall et al. 2001) and pass larger ejaculates (Powell et al. 1974, MacDiarmid \& Bulter 1999) even after a number of successive matings (Jivoff 1997). Males deplete their sperm reserves and decrease the amount of ejaculate passed to females after successive matings (Jivoff 1997). Therefore, sperm limitation would occur in crab populations when large males are selectively harvested, and the reproductive success of the crab stocks may be restricted. However, there is little evidence indicating that sperm limitation occurs in fished populations.

Some other factors also influence the fertilization rate of females via sperm limitation. First, the recovery rate of male sperm resources influences the degree of sperm limitation for females. For example, as seen in finches (Birkhead 1991), if the recovery of male sperm resources is rapid, the males complete a number of successive matings. On the contrary, if the recovery rate is low, males deplete their sperm reserves, especially in populations with few males. Second, the degree of sperm limitation would also vary with some crustacean female reproductive characteristics. For example, as seen in blue crabs (Millikin \& Williams 1980) and the spiny king crab (Sato et al. 2005), if a female is non-receptive to re-mate or has no spermatheca to store sperm received from a male (that is, an external fertilizer), the female would be prone to be limited in the number of sperm available to fertilize her eggs. In addition, if females spawn a large number of eggs or produce multiple clutches using sperm acquired during 1 mating, the shortage in number of sperm for fertilization would greatly impact on their fertility (Waddy \& Aiken 1986, Paul \& Paul 1992).

The spiny king crab Paralithodes brevipes occurs off northern Japan in the Sea of Okhotsk and in the Bering Sea (Miyake 1982), and is an important fishery resource off eastern Hokkaido; however, the catch numbers have declined in recent years. Little is known about the reproductive ecology of this crab. Our laboratory observations have shown that males can mate many times in a reproductive season, and both females and males can have multiple reproductive seasons during a lifetime. Males perform pre-copulatory mate guarding behavior with mature females in the reproductive season from late April to late May. In laboratory experiments, pre-copulatory mate guarding lasts for $38.6 \pm 24.9 \mathrm{SD}$ h (Wada et al. 1997, 2000). Females molt once in a reproductive season and mate once immediately after molting (Wada et al. 1997). Spawning usually occurs within $1 \mathrm{~h}$ after mating ( $\mathrm{T}$. Sato et al. unpubl. data) and females incubate a large clutch for about 11 mo (Sato \& Abe 1941). Males store many spermatophores containing only sperm in the vasa deferentia (Sato et al. 2004). We have observed spermatocytes in the testis but not in the vasa deferentia, spermatozoa (i.e. unpackaged sperm) in both, and packaged sperm only in the vasa deferentia. Thus, in this species, sperm produced in the testis are transmitted to the vasa deferentia, where they are packaged into spermatophores. Sperm in the spermatophores are the only sperm available during mating and are immobile due to a lack of flagella ( $T$. Sato et al. unpubl. data). Males attach spermatophores onto the abdomen of females near the gonopores because females do not have spermatheca to store the sperm (T. Sato et al. unpubl. data). Mated females fertilize their eggs externally within the brood-chamber formed by a flap under the body (Sato \& Abe 1941). Since female spiny king crabs have no spermatheca, mate once and spawn a large clutch, they are susceptible to sperm limitation. However, little is known about male reproductive potentials and the recovery rate of the male sperm resource in this crab, and we do not know whether or how the present fishery regulations have influenced the reproductive success of crab stocks via sperm limitation.

Fishing for this crab began in about 1935 off eastern Hokkaido (Sato \& Abe 1941). Until 1980, fishing was unregulated, but due to declining catches, all fishery activities for this crab were suspended completely between 1981 and 1983. In this study, we used carapace length (CL) as an index of body size. Carapace width $(\mathrm{CW})$ was translated into $\mathrm{CL}$ based on the rela- 
tionship between CL and CW shown by Mori (1993). From 1984, all females were protected from fishing and only males of about $86.8 \mathrm{~mm}$ CL could be fished. In 1987, only males larger than $80 \mathrm{~mm} \mathrm{CL}$ and females larger than $100 \mathrm{~mm}$ CL without a clutch could be fished. Since 1991, only males larger than about $69.7 \mathrm{~mm}$ CL have been collected. The difference in the minimum legal size between 1990 and 1991 was the largest, and the minimum legal size has not been changed since 1991. The population structure of this crab will, therefore, have changed rapidly in response to fishing over this period. Landings of the crab have still declined in spite of the application of the present fishery regulations.

Fishing starts every year on April 1 off the coast of Hamanaka, Hokkaido, Japan (4330' N, $\left.145^{\circ} 60^{\prime} \mathrm{E}\right)$. Sex-selective and size-selective fishing can cause a decrease in the size of males available for mating and skew the sex ratio towards females in fished populations, which would result in a disproportionate number of smaller males mating with the unfished females. To understand the influences of the sex-selective and size-selective fishing on the reproductive success of this species, it is important to examine the effects of male mating frequency and male size on the reproductive potential of males and the recovery rate of the male sperm resource for this crab. Similarly, it is necessary to investigate rapid changes in the fished crab population structure due to fishing and the degree of depletion of the sperm reserved by males in the fished population. This would allow us to see whether the present fishery regulation has influenced the reproductive success of the crab stocks via sperm limitation.

In this study, we investigated the possibility that sperm limitation occurs in fished populations of the spiny king crab by (1) examining the influence of male mating frequency and male size on their reproductive potential (ejaculate size, spawning success of females and fertilization rate depending on male mating frequency, and the relationship between the ability of successive mating and male size), (2) examining the recovery rate of exhausted sperm resources, (3) comparing the population structure altered by the present fishing regulations (in 1991 and 1992) with that of a less selectively fished population (in 1989 and 1990), and (4) investigating the number of sperm retained by males before, during and after the reproductive season in a fished population.

\section{MATERIALS AND METHODS}

All laboratory experiments were conducted at the Akkeshi Station of the Incorporated Administrative Agency, Fisheries Research Agency, National Center for Stock Enhancement, Hokkaido, Japan from 1999 to 2003. At this station, many mature spiny king crabs are reared to produce seed crabs for a stock enhancement program. Mature crabs were collected off eastern Hokkaido. Only intact individuals with all of their limbs were used for these experiments. Reared crabs were fed shishamo smelt Hypomesus japonicus, shortneck clams Ruditapes philippinarum and sand shrimps Crangon spp. During the experiments, a light:dark regime matched the local conditions, the water temperature ranged from -0.6 to $4.3^{\circ} \mathrm{C}$, and filtered, aerated seawater flowed through all the tanks. Before the reproductive season, all males were isolated from females to insure they had not mated. The CL of each male and female was measured, and each individual was marked with a label or paint. We marked a small and very limited area on the carapace of the crabs with paint, and conducted experiments with the marked individuals long after they were painted. Therefore, we think that the marking with paint had no effect on the behavior of the crabs. Females were re-marked with a label after they molted. We analyzed the population structure of fished populations in Hamanaka, Hokkaido, Japan from 1989 to 1992, and collected crabs to investigate the number of sperm retained by male crabs.

Influence of male mating frequency and male size on male reproductive potential. First, we examined the influence of male mating frequency on the amount of ejaculated sperm. To avoid an influence of male size and mate size on ejaculate size, males and females were size-matched. Each male (CL: 80.0 to $83.6 \mathrm{~mm}$, $\mathrm{n}=7$ ) was placed into a separate circular aquarium $\left(0.5 \mathrm{~m}^{3}\right)$. Unmolted female (pre-molting CL: 100.0 to $107.7 \mathrm{~mm}, \mathrm{n}=21)$ crabs were placed into a tank $\left(8 \mathrm{~m}^{3}\right)$. We observed the female tank every morning at 08:30 $\mathrm{h}$ to check whether the females had molted. If the females had molted, we transferred them into a circular aquarium to mate with a male.

We then observed the male and molted female until they mated. The mated female was removed from the water just after mating, and the spermatophores were removed from its abdomen by cutting out parts of the female exoskeleton where the spermatophores were attached. In this study, we used a method of counting the number of sperm by using $20 \% \mathrm{NaOH}$ solution to extract sperm from the spermatophores (Sato et al. 2004). These parts of the female exoskeleton were put into one $15 \mathrm{ml}$ tube filled with $10 \mathrm{ml}$ of $20 \% \mathrm{NaOH}$ solution. After soaking in the $\mathrm{NaOH}$ solution for $60 \mathrm{~min}$, the tube contents were mixed using a vortextype mixer. The mixed solution was immediately placed in a Thoma hemacytometer, and the solution was allowed to settle for $3 \mathrm{~min}$. The sperm in $0.1 \mu \mathrm{l}$ of the solution were then counted under an optical micro- 
scope at $400 \times$ magnification with medium-high light. The total number of ejaculated sperm was calculated as: (number of sperm counted/volume of $\mathrm{NaOH}$ counted [i.e. $0.1 \mu \mathrm{l}]) \times$ total volume (i.e. $10 \mathrm{ml}$ ). Four sub-samples of $0.1 \mu \mathrm{l}$ were taken and counted for each tube. The average of the 4 counts was used as the number of ejaculated sperm. Each male mated with 1 female per day, and mated with 3 females within $3 \mathrm{~d}$. We collected all spermatophores from each mating. The effect of male mating frequency on the amount of ejaculated sperm was analyzed by repeated-measures ANOVA and the Dunnett test after testing by the Mauchly's sphericity test.

Second, we examined the influences of male mating frequency on the spawning success of females and the fertilization rate. We used 17 males (CL: 80.0 to $85.0 \mathrm{~mm}$ ) and 75 unmolted females (pre-molting CL: 100.0 to $110.0 \mathrm{~mm})$. The rearing conditions of these individuals were the same as for the first experiment. After transfer of the molted female into a male's circular aquarium, we checked whether the molted female had spawned every morning at 08:00 h. When molted females did not spawn within 2 d after transfer, the female was checked for spermatophores attached to her abdomen. If no spermatophores were observed, the female was transferred to another tank $\left(8 \mathrm{~m}^{3}\right)$ that contained over 30 males to determine if the cause of the spawning failure was due to the male or the female. If the female spawned and had a fertilized clutch in the tank with 30 males, we assumed that the male in the circular aquarium was the cause of the spawning failure. After spawning, the spawned female was moved from the circular aquarium to another tank $\left(8 \mathrm{~m}^{3}\right)$ that contained no males, and another molted female was transferred to the circular aquarium the next day. Each male mated with 1 female per day, and finally mated with 5 females in succession or until the male became incapable of inducing females to spawn within $2 \mathrm{~d}$. A preliminary examination revealed that all males that induced females to spawn successfully did mate with the molted female by $2 \mathrm{~d}$ after her molt. Males that did not induce females to spawn even after more than $2 \mathrm{~d}$ could not induce the female to spawn eventually. That is, males that did not induce females to spawn within $2 \mathrm{~d}$ after molting were defined as males that had already lost their ability to mate with a female. So we used the $2 \mathrm{~d}$ after her transfer as the time limit for the male to mate. After the spawned eggs had divided into 32 cells (that is, about $12 \mathrm{~d}$ after spawning, T. Sato et al. unpubl. data), 150 eggs were randomly collected from 3 parts of the clutch using a pair of tweezers, and observed for cell division under a stereomicroscope. We used the percentage of dividing eggs as the fertilization rate of the clutch.

The effect of male mating frequency on the spawning success was analyzed by the Friedman test with dummy variables. In this analysis, if a male induced a female to spawn successfully, it was scored as '1', and, if the male did not induce the female to spawn, it was scored as ' 0 '. We, thereby, analyzed data of 17 males by both the Friedman test and the Dunnett test. The effect of male mating frequency on the fertilization rate was also analyzed by the Friedman and Dunnett tests.

Third, we examined the relationship between the ability to successively mate and male size. We used 26 males in 5 size classes (CL: 74.2 to $128.5 \mathrm{~mm}$; CL: 70 to $80 \mathrm{~mm}$ class, $\mathrm{n}=2$; CL: 80 to $90 \mathrm{~mm}$ class, $\mathrm{n}=3$; CL: 90 to $100 \mathrm{~mm}$ class, $\mathrm{n}=5$; CL: 100 to $110 \mathrm{~mm}$ class, $\mathrm{n}=5$; CL: 110 to $120 \mathrm{~mm}$ class, $\mathrm{n}=5$; CL $>120 \mathrm{~mm}$ class, $\mathrm{n}=$ 6). Each male was placed in an aquarium with 5 females; that is, 130 females (CL: 77.5 to $118.8 \mathrm{~mm}$, average CL: $99.6 \pm 8.3 \mathrm{SD} \mathrm{mm}$ ) were used. Several stones were placed in the aquarium as substrate.

The reproductive behavior of males, molting of females, mating and spawning were recorded in all aquaria every morning at 08:00 h. If a female molted, we checked whether it had spawned. When molted females did not spawn within 2 d after molting, we examined whether the cause of the spawning failure was due to the male or the female by the same method used in the second experiment. The fertilization rate in each spawning was also examined by the same method used in the second experiment. The relationship between male size and degree of decrease in female spawning success with increasing mating frequency was analyzed using the log-rank test (Lawless 1982).

Recovery rate of exhausted sperm. Each male (CL: 80.0 to $85.0 \mathrm{~mm}, \mathrm{n}=16$ ) was placed into a separate circular aquarium $\left(0.5 \mathrm{~m}^{3}\right)$. Unmolted females (pre-molting CL: 100.0 to $110.0 \mathrm{~mm}, \mathrm{n}=78$ ) were placed in an aerated tank $\left(8 \mathrm{~m}^{3}\right)$. We observed the $8 \mathrm{~m}^{3}$ tank every morning at $08: 30 \mathrm{~h}$ to check whether females had molted. If the females had molted, we transferred them to a circular aquarium with a male. Every male was given access to 1 molted female each day until the male could not induce a molted female to spawn within $2 \mathrm{~d}$ after the female was transferred. These males were categorized as 'depleted males'.

At 0, 14 and $28 \mathrm{~d}$ after depletion, the vasa deferentia and testis were removed from the depleted males and put into a $50 \mathrm{ml}$ tube filled with $40 \mathrm{ml}$ or $10 \mathrm{ml}$ of $20 \%$ $\mathrm{NaOH}$ solution, depending on the size of the removed vasa deferentia or testis. After soaking in $\mathrm{NaOH}$ solution for $120 \mathrm{~min}$, the tube contents were mixed using a vortex-type mixer. We extended the soaking time in the $\mathrm{NaOH}$ solution from the time used in the experiment to count the number of ejaculated sperm because spermatophores were enveloped in the vasa deferentia. The total number of sperm in the vasa deferentia or the testis was counted and estimated by the same method used to 
count the number of ejaculated sperm. Linear regressions were used to determine the relationships between the number of sperm in the vasa deferentia or the testis and the number of days after depletion of the males.

To estimate the recovery rate of exhausted sperm available to mate, the vasa deferentia were removed from 11 unmated males (CL: 81.0 to $85.0 \mathrm{~mm}$ ) before the reproductive season in late April. We counted the number of sperm retained by the unmated males using the same method. The number of sperm retained by unmated males was compared with those of males isolated from females for $28 \mathrm{~d}$ using a $t$-test after testing for homogeneity of variances using the Levene test.

Population structure altered by the fishery. Field investigations of the population structure of a fished population were conducted by the staff of the Kushiro Fisheries Experimental Station off the coast of Hamanaka from 1986 to 1992. Crabs were caught in crab pots at various sites and depths $(<40 \mathrm{~m})$ in late May. The sex and size were recorded for each crab, and we then analyzed the population structures for late May from 1989 to 1992. In 1991, the fishery management for spiny king crab reduced the minimum legal size from 80 to about $69.7 \mathrm{~mm}$ CL. Since the sampling efforts in 1989 and 1990 were less than those in 1991 and 1992, we calculated the size distribution and abundance of the caught crabs per unit sampling effort (10000 crab pots were used for sampling per day) to compare the population structures before and after the change in fishing regulations. First, to understand the influence of the change of the minimum legal size on mean male size in the fished population, we compared the mean male size before and after the regulation change. Since the population structure can be influenced by various factors (e.g. environmental and/or anthropogenic factors), the population would be expected to show some variation in its population structure between years. To remove this annual variation in population structure between years, we compared the mean male size during 1989 and 1990 with that from 1991 and 1992. The Mann-Whitney $U$-test was used for the comparison because of the heterogenous variances of the data set. Furthermore, we also compared the mean female size in 1989 and 1990 with that from 1991 and 1992 with the same method used for males. Second, to understand the influence of present fishery regulations on the population structure, we compared the size distributions of males with those of females in each year between 1989 and 1992 using the Kolmogorov-Smirnov test.

Number of sperm retained by males. We examined the relationship between male size and the number of sperm in the vasa deferentia or the testis, and the temporal change in the number of sperm that were retained by males in the fished population during the reproductive season. Male crabs were collected before (late April), during (early-middle May) and after the reproductive season (late May) in 2002 and 2003. Small crabs (CL $<69.7 \mathrm{~mm}$ ) were caught in crab pots at various sites and depths $(<40 \mathrm{~m})$ off the coast of Hamanaka. Large crabs (>69.7 mm) were bought from fishermen who also harvested male crabs off the coast of Hamanaka. Only intact males with all of their limbs and unmolted males in the intermolt stage were used to count the number of sperm.

The collected crabs (CL: 53.7 to $109.4 \mathrm{~mm}$, $\mathrm{n}=234$ ) were transported to the Akkeshi Station of the National Center for Stock Enhancement. The vasa deferentia and testis were removed from each crab under a stereomicroscope and put into $50 \mathrm{ml}$ tubes with $40 \mathrm{ml}$ or $10 \mathrm{ml}$ of $20 \% \mathrm{NaOH}$ solution, depending on the size of the vasa deferentia or testis. The total number of sperm in the vasa deferentia or the testis was estimated by the same method used to determine the recovery rate of exhausted sperm. After log transformation, simple linear regressions were used to determine the relationship between the number of sperm in the vasa deferentia or the testis and male size. ANCOVA was conducted, assigning male size as the covariate to investigate the influence of male size on the relationship between number of sperm in the vasa deferentia and that in the testis, and to examine the temporal variation of the number of sperm in the testis reserved by males in the fished population. Since the regression was not significant, the temporal variation of the number of sperm in the vasa deferentia reserved by males was analyzed by 1-way ANOVA and the TukeyKramer test after testing for homogeneity of variances by the Levene test.

To evaluate the number of sperm available for mating retained by males in the fished population, we counted the sperm reserved by depleted males in the fished population in the laboratory experiment. We counted and calculated the number of sperm in the vasa deferentia retained by depleted males (CL: 80.8 to $103.6 \mathrm{~mm}$, $\mathrm{n}=8$ ) using the same method as for the recovery rate of exhausted sperm. We then compared the mean number of sperm in the vasa deferentia retained by depleted males with that retained by males in the fished population within each season. If the number of sperm retained by a male in the fished population was less than that of the depleted males, we defined the male as 'depleted'. Thereby, we investigated the temporal change in the proportion of depleted males within reproductive season using the $\chi^{2}$ test and the relationship between male size and the proportion of depleted males within each season (during and after reproductive season) in the reproductive season using the Fisher's exact test or the $\chi^{2}$ test. In this analysis, we classified males as 'small' (CL: 80 to $90 \mathrm{~mm}$ ) or 'large' (CL > $90 \mathrm{~mm})$. 


\section{RESULTS}

\section{Influences of male mating frequency and male size on male reproductive potential}

Ejaculate size, the percentage of spawning success of females and fertilization rate decreased with increasing male mating frequency. In the experiments on the influence of male mating frequency, we collected 21 ejaculated spermatophores (first mating: $\mathrm{n}=7$, second mating: $\mathrm{n}=7$, third mating: $\mathrm{n}=7$ ) and examined the fertilization rate for 15 clutches (first mating: $n=5$, second mating: $\mathrm{n}=5$, third mating: $\mathrm{n}=5$ ). Male mating frequency had a significant effect on the ejaculate size (repeated-measures ANOVA, $F_{2,12}=91.97, \mathrm{p}<0.001$, Fig. 1). The Dunnett test showed significant differences between the first and second ( $p<0.001)$, and the first and third matings $(p<0.001)$. Male mating frequency also had a significant effect on the percentage of spawning success of females (Friedman test, $\chi^{2}=39.68$, $\mathrm{df}=4, \mathrm{p}<0.001$, Fig. 2). The Dunnett test showed significant differences between the first and third $(\mathrm{p}=$ $0.029)$, the first and fourth ( $p<0.001)$, and the first and fifth matings $(p<0.001)$. The fertilization rate was also influenced significantly by male mating frequency (Friedman test, $\chi^{2}=6.63, \mathrm{df}=2, \mathrm{p}=0.036$, Fig. 3 ). The Dunnett test showed significant differences between the first and third matings $(\mathrm{p}=0.025$. The proportion of females that did not spawn in the circular aquarium $\left(0.5 \mathrm{~m}^{3}\right)$ increased with increasing male mating frequency, but all these unmated females spawned after their transfer to the tank $\left(8 \mathrm{~m}^{3}\right)$ that contained over 30 males. Therefore, all the spawning failures were attributed to each male in the circular aquarium.

In the examination of the relationship between the ability of successive mating and male size, 125 females molted in the circular aquarium $\left(1 \mathrm{~m}^{3}\right)$, but 21 of them did not spawn (CL: 70 to $80 \mathrm{~mm}$ class, $\mathrm{n}=6$; CL: 80 to

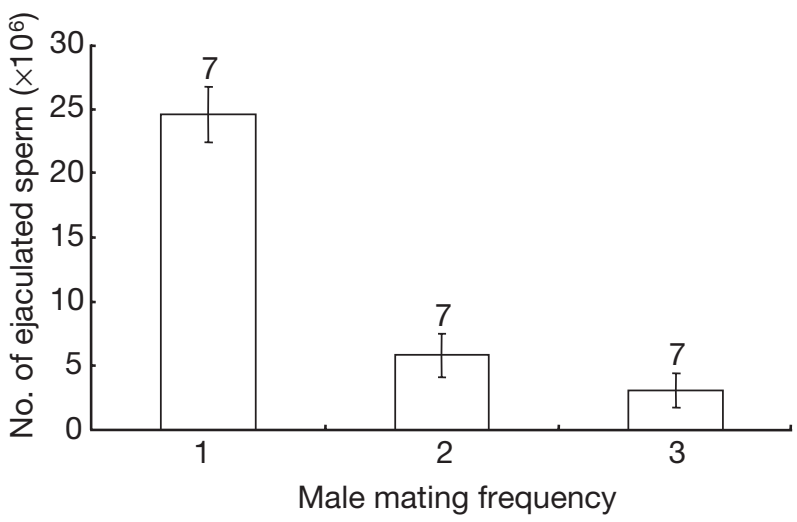

Fig. 1. Paralithodes brevipes. Relationship between male mating frequency and number of ejaculated sperm. Each number above the plots indicates sample size. Error bars represent SE

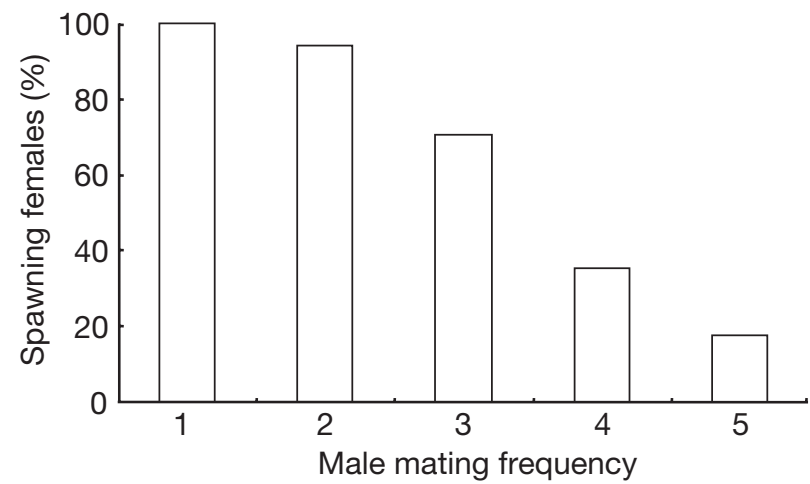

Fig. 2. Paralithodes brevipes. Relationship between male mating frequency and percentage of spawning females

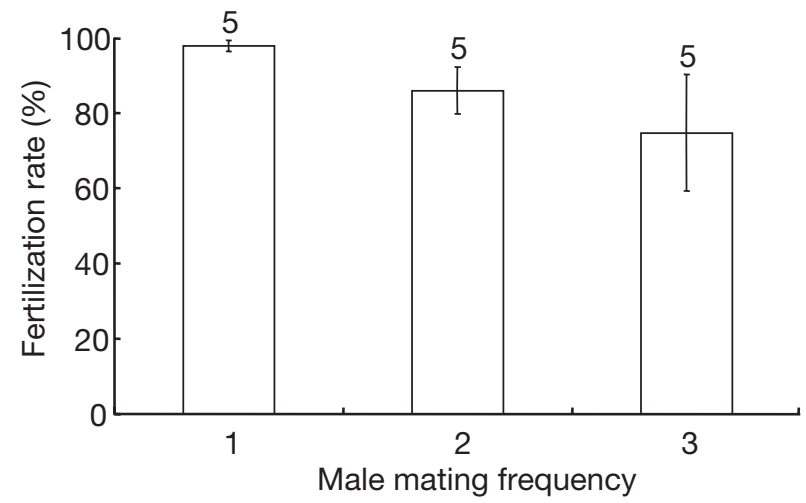

Fig. 3. Paralithodes brevipes. Relationship between male mating frequency and fertilization rate. Each number above the plots indicates sample size. Error bars represent SE

$90 \mathrm{~mm}$ class, $\mathrm{n}=5$; $\mathrm{CL}$ : 90 to $100 \mathrm{~mm}$ class, $\mathrm{n}=4$; $\mathrm{CL}>$ $120 \mathrm{~mm}$ class, $\mathrm{n}=6$ ). Some females repeatedly showed mating behavior with a male in each circular aquarium but did not spawn. These 21 females were transferred to a tank $\left(8 \mathrm{~m}^{3}\right)$ that contained over 30 males. Nineteen of the females spawned. Therefore, most spawning failures were attributed to the male in each circular aquarium. Two non-spawning females were excluded from the analysis. Only males in the 100 to $120 \mathrm{~mm} \mathrm{CL}$ class mated and induced all females to spawn. The degree of decline in percentage of spawning success of females, with increasing male mating frequency differed significantly between the male size classes (logrank test, $\chi^{2}=15.60, \mathrm{df}=5, \mathrm{p}=0.008$, Fig. 4). Small males in the 70 to $90 \mathrm{~mm}$ CL class mated and induced females larger than themselves by about $30 \mathrm{~mm}$ CL to spawn, but did not hold the females fast during the pre-copulatory guarding behavior. Males larger than $120 \mathrm{~mm}$ CL showed a decrease in percentage of success to induce females to spawn with increasing male mating frequency as with the small males (Fig. 4).

Of the 104 females that spawned in each circular aquarium, 4 died before we calculated the fertilization 


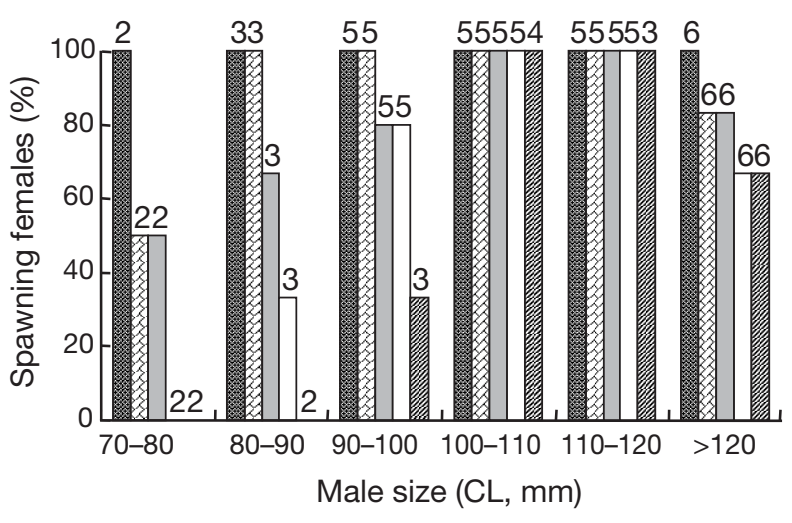

FEMALE: 圂 First 图 Second $\square$ Third $\square$ Fourth 恡 Fifth

Fig. 4. Paralithodes brevipes. Relationship between mating frequency by males of various body sizes and percentage of spawning females. Each number above the graph indicates sample size

rate of their clutches. One other female spawned an unfertilized clutch; as we did not know whether the female had mated with a male, we excluded this female from the analysis. A total of 99 spawning females were examined to determine the fertilization rate (Fig. 5). Due to insufficient sample sizes, we could not statistically compare the fertilization rates of each clutch between male size classes. However, the relationship between fertilization rate and male mating frequency showed different tendencies between the male size classes (Fig. 5). Especially with small males (CL: 80 to $100 \mathrm{~mm}$ ), a large variation in the fertilization rate was seen with increasing male mating frequency. Compared with larger males (CL > 100 mm), these values were relatively low. However, large males (CL > $100 \mathrm{~mm}$ ) showed a small decrease in fertilization rate,

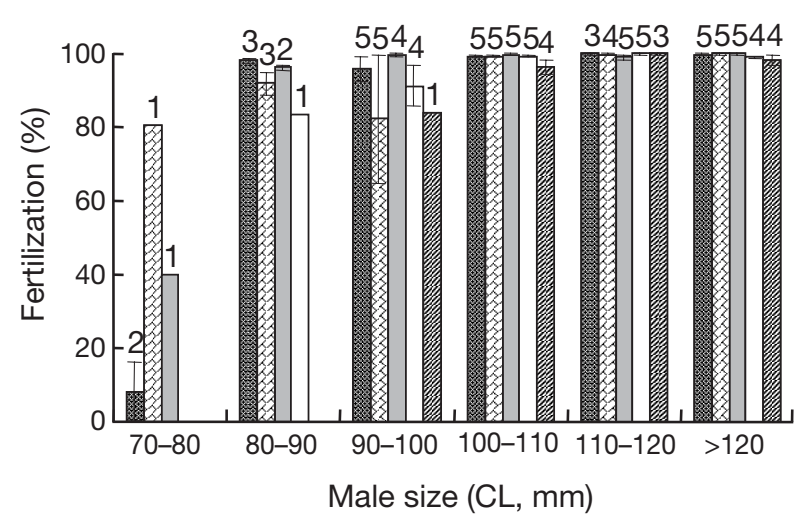

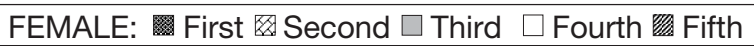

Fig. 5. Paralithodes brevipes. Relationship between mating frequency by males of various body sizes and fertilization rate. Each number above the graph indicates sample size. Error bars represent SE but always at high values (Fig. 5). The smallest males (CL: 70 to $80 \mathrm{~mm}$ ) showed a large variation among the male mating frequency (Fig. 5).

\section{Recovery rate of exhausted sperm}

The number of sperm in the vasa deferentia and the number of days after males became incapable of mating showed no relationship $\left(y=0.061 x+10.50, r^{2}=0.024, n=\right.$ 16, $\mathrm{p}=0.57$, Fig. 6). After males became depleted, some sperm remained in the vasa deferentia. There was a significant difference in the number of sperm in the vasa deferentia between unmated males and males allowed $28 \mathrm{~d}$ to recover after becoming depleted ( $t$-test, $t=7.78$, $\mathrm{df}=14, \mathrm{p}<0.001$, Fig. 6). Thus, the number of sperm in the vasa deferentia did not recover even after $28 \mathrm{~d}$ after the depletion. On the contrary, a significant positive relationship existed between the number of sperm in the testis and the number of days after males became incapable of mating $\left(y=1.036 x+39.04, r^{2}=0.25, n=16\right.$, $\mathrm{p}=0.046$, Fig. 6), suggesting accumulation of sperm reserves in the testis.

\section{Altered population structure due to fishery}

Mean male size differed significantly between 1989 and 1990, and 1991 to 1992 (Mann-Whitney $U$-test, $z=$ $-10.56, \mathrm{p}<0.001$; before the change: $76 \pm 11.0 \mathrm{~mm} \mathrm{SD}$ $\mathrm{CL}$; after the change: $68 \pm 8.90 \mathrm{~mm}$ SD CL). In addition, larger males just above the new legal size (CL $\approx$ $69.7 \mathrm{~mm}$ ) decreased sharply in 1991 and 1992 (Fig. 7). In contrast, mean female size in 1991 and 1992 was significantly larger than that in 1989 and 1990 (MannWhitney $U$-test, $z=-10.42, \mathrm{p}<0.001$; before the change: $74 \pm 10.0 \mathrm{~mm}$ SD CL; after the change: $80 \pm$

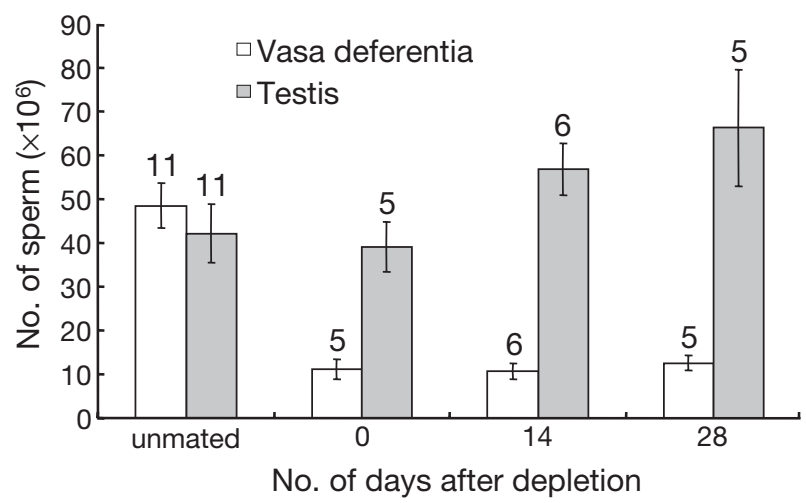

Fig. 6. Paralithodes brevipes. Recovery rate of the number of sperm in the vasa deferentia or the testis, and the number of sperm in the vasa deferentia or the testis retained by unmated males. Each number above the graph indicates sample size. Error bars represent SE 

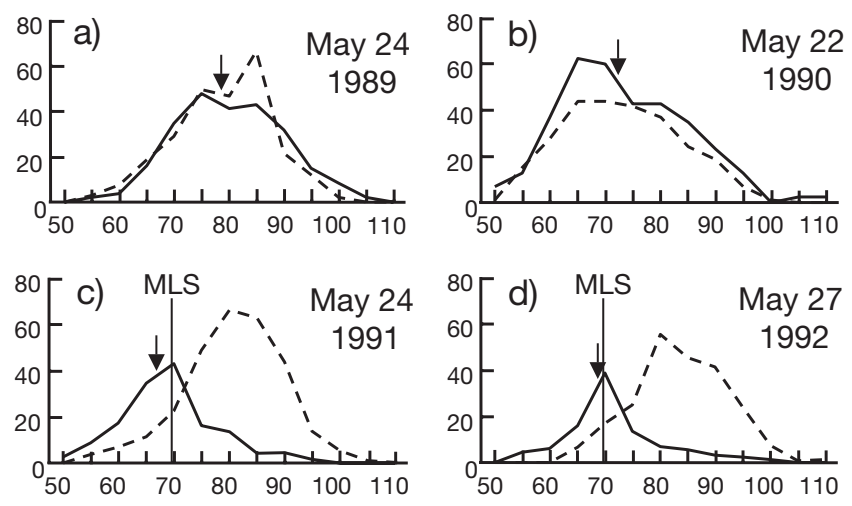

Carapace length $(\mathrm{mm})$

\section{Male -.-- Female}

Fig. 7. Paralithodes brevipes. Size distributions of males and females in late May of 1989 to 1991 (a-d) off the coast of Hamanaka per definite sampling efforts $\left(10000 \mathrm{crab}\right.$ pots $\left.\mathrm{d}^{-1}\right)$. MLS in (c) and (d) indicates the minimum legal size ( $\sim 69.7 \mathrm{~mm}$ $\mathrm{CL}$ ). Each arrow indicates the annual average of male CL

$8.70 \mathrm{~mm}$ SD CL). Despite this increase in the mean female size after the change in fishing regulations, only the mean male size significantly decreased, indicating that the new regulations influenced and decreased the mean male size.

In 1989 and 1990, there was no significant difference in size distribution between males and females (Kolmogorov-Smirnov test, in 1989: $\mathrm{df}=2, \mathrm{o}^{7}: \mathrm{n}=262$, o: $\mathrm{n}=$ 274, $\chi^{2}=4.75, \mathrm{p}=0.186$, Fig. 7a; in 1990: $\mathrm{df}=2, \mathrm{o}^{7}: \mathrm{n}=$ 294, o: $\mathrm{n}=226, \chi^{2}=0.60, \mathrm{p}>0.99$, Fig. 7b). But in 1991 and 1992, after the change in regulation, the size distributions between males and females differed significantly (Kolmogorov-Smirnov test, in 1991: df = 2, $0^{7}: \mathrm{n}=$ 381, o: $\mathrm{n}=749, \chi^{2}=339.06, \mathrm{p}<0.001$, Fig. $7 \mathrm{c}$; in 1992: $\mathrm{df}=2, \mathrm{o}^{7}: \mathrm{n}=241, \mathrm{o}: \mathrm{n}=499, \chi^{2}=261.14, \mathrm{p}<0.001$, Fig. $7 \mathrm{~d}$ ). Both the mean body size and abundance of females were apparently larger than those of males after the change in regulation (Fig. 7).

\section{Number of sperm reserved by males}

The number of sperm in the vasa deferentria and the testis increased significantly with increasing male size (vasa deferentia: $y=4.87 x-1.66, \mathrm{r}^{2}=0.73, \mathrm{n}=95, \mathrm{p}<$ 0.001 ; testis: $y=3.35 x+1.17, \mathrm{r}^{2}=0.48, \mathrm{n}=94, \mathrm{p}<0.001$, Fig. 8). In addition, as males got larger, they stored more sperm in their vasa deferentia relative to their testis than the smaller males (ANCOVA: male size $x$ reservoirs: $F_{1,185}=10.33, p=0.002$, Fig. 8).

Regardless of season (before, during and after the reproductive season), the number of sperm in the testis

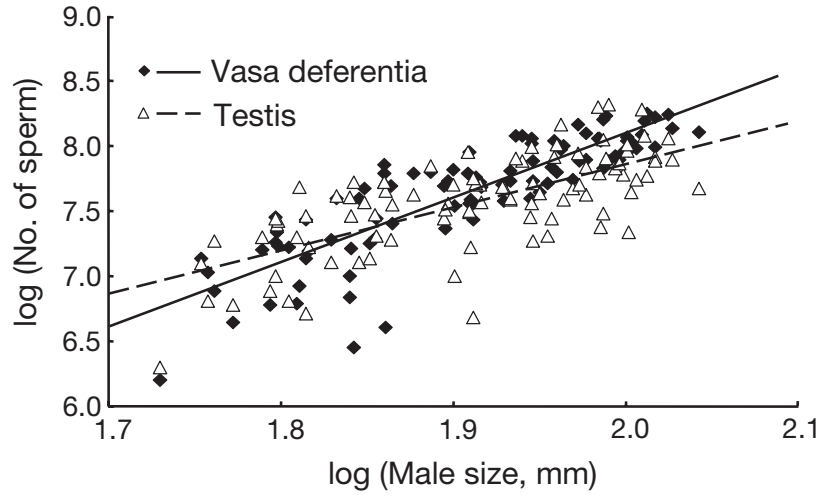

Fig. 8. Paralithodes brevipes. Relationships between male size and the number of sperm in the vasa deferentia or the testis retained by males

consistently showed a stable pattern throughout the reproductive season (ANCOVA: $F_{2,179}=0.44, \mathrm{p}=0.44$, Fig. 9). The regression was not significant for the number of sperm in the vasa deferentia after the reproductive season. There was a significant difference in the number of sperm in the vasa deferentia among seasons (1-way ANOVA: $F_{2,231}=29.53, \mathrm{p}<0.001$, Fig. 10). The TukeyKramer test showed that the number of sperm in the vasa deferentia decreased significantly throughout the reproductive season.

In the laboratory experiments, there was no significant difference in the mean number of sperm in the vasa deferentia retained by depleted males $(12.22 \times$ $10^{6} \pm 4.39 \times 10^{6} \mathrm{SD}, \mathrm{n}=8$ ) regardless of male size ( $t$-test, $t=-0.95, \mathrm{df}=6, \mathrm{p}=0.38)$. We defined males having fewer sperm than average (i.e. $<12.22 \times 10^{6}$ ) as depleted males, and many males in the field were classified as depleted (percentages of depleted males: late April, $0 \%, \mathrm{n}=55$; early-middle May, $11.5 \%, \mathrm{n}=$

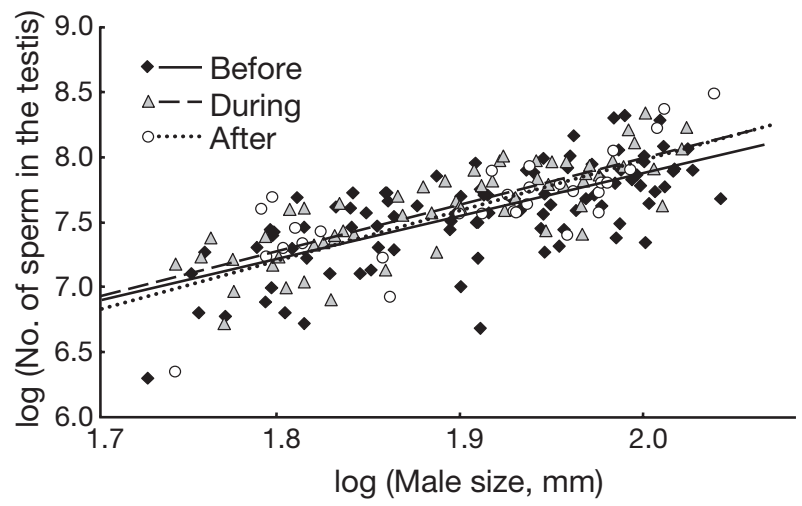

Fig. 9. Paralithodes brevipes. Relationship between male size and the number of sperm in the testis retained by males before (late April), during (early-middle May) and after (late May) the reproductive season (before: $y=3.35 x+2.69, \mathrm{r}^{2}=$ 0.48, $\mathrm{n}=94$; during: $y=3.71 \mathrm{x}+1.324, \mathrm{r}^{2}=0.67, \mathrm{n}=60$; after: $\left.y=3.96 x+0.12, \mathrm{r}^{2}=0.59, \mathrm{n}=31\right)$ 


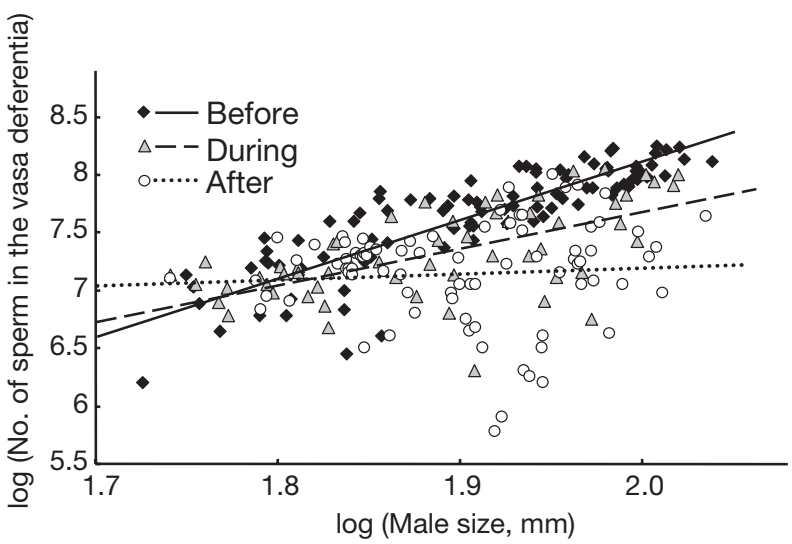

Fig. 10. Paralithodes brevipes. Relationship between male size and the number of sperm in the vasa deferentia retained by males before (late April), during (early-middle May) and after (late May) the reproductive season

26; late May, 42.2\%, $\mathrm{n}=45$, Fig. 11). These percentages were calculated from the data of males larger than $80 \mathrm{~mm}$ CL because some males smaller than $80 \mathrm{~mm}$ CL had sperm numbers below the average of depleted males even before the reproductive season. The proportion of depleted males increased significantly throughout the season $\left(\chi^{2}\right.$ test, $\chi^{2}=31.413, \mathrm{df}=$ $2, \mathrm{p}<0.0001$; no. of depleted males:no. of nondepleted males $=0: 55$ [before], 3:23 [during] and 19:26 [after]).

During the reproductive season, male size had no influence on the proportion of depleted males (Fisher's exact test, $\chi^{2}=0.38, \mathrm{df}=1, \mathrm{p}>0.99$; no. of depleted males:no. of non-depleted males $=2: 11$ [small males] and 1:12 [large males]). In contrast, just after the reproductive season, the proportion of depleted males in the small size class was significantly larger than that in the large size class $\left(\chi^{2}\right.$ test, $\chi^{2}=5.47, \mathrm{df}=1, \mathrm{p}=0.019$; no. of depleted males:no. of non-depleted males $=14: 10$ [small males] and 5:16 [large males]).

\section{DISCUSSION}

Our results suggest that male mating frequency and male size are factors greatly influencing the intensity of sperm limitation in the spiny king crab. The male mating frequency strongly affected the reproductive success of females. The percentage of spawning success of females, the fertilization rate, and the number of ejaculated sperm decreased with increasing male mating frequency. Thus, the decreasing percentage of spawning success of females and fertilization rate was likely caused by an insufficient sperm supply; that is, sperm limitation. Increased male mating frequency increases the probability that sperm limitation will occur.

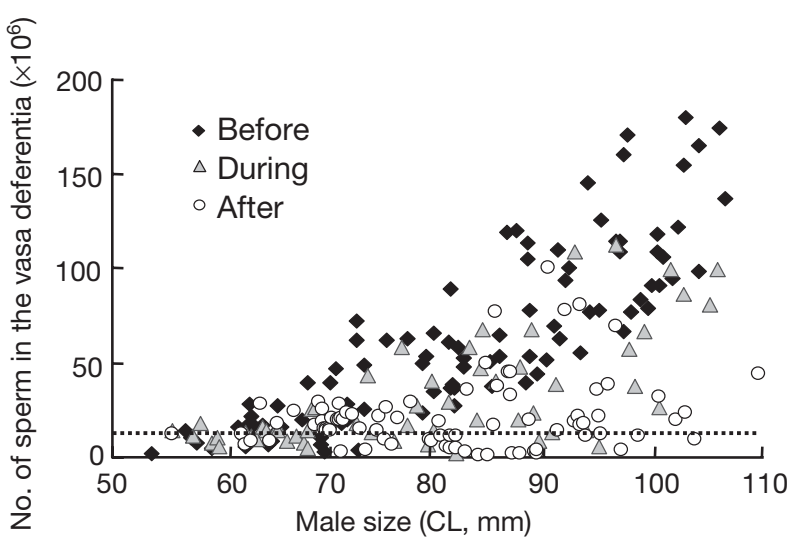

Fig. 11. Paralithodes brevipes. Variance of proportions of depleted males throughout the reproductive season. The horizontal dotted line indicates the mean of the number of sperm in the vasa deferentia retained by males that depleted their sperm reserves (i.e. $12.22 \times 10^{6}$ )

Male size was another factor influencing the reproductive success of females. Changes in the percentage of spawning success of females and in the fertilization rate with increasing male mating frequency differed between the male size classes. Compared with the smaller males, the larger males had a superior ability to mate with females and fertilize their clutches successively. Thus, there was an interaction between the effects of male size and male mating frequency on the reproductive success of females, which means male spiny king crabs have a size-dependent reproductive potential. The size-dependent reproductive potential in males possibly results from the fact that there were many sperm in the vasa deferentia of larger males compared with smaller ones. In other species of crabs, larger males have more numerous sperm than smaller males (e.g. Kwei 1978, Sapelkin \& Fedoseev 1986, Jivoff 1997), and larger males also provide a larger ejaculate to females compared with smaller males and pass many sperm even after successive mating (Jivoff 1997). In addition, in the spiny king crab, the degree of decrease in the number of ejaculated sperm with increasing mating frequency may differ among male size classes, which may cause the differences in percentage of spawning success of females and the fertilization rate between male size classes. In the fished population, the difference between male sperm stores before the reproductive season and that after the reproductive season was greater for large males than for small males, which may suggest large males provide more sperm to females. Male mating frequency and male size must be taken into consideration when we reconsider the management of the fished spiny king crab populations.

Can we assert that sperm limitation is actually occurring? Generally, male size and male mating frequency 
influence not only the quantity but also the quality of ejaculate (e.g. Pitnick \& Markow 1994, Bissoondath \& Wiklund 1996), which influences fertilization. We do not know whether sperm within an ejaculate vary in spiny king crab. There may be a difference in sperm quality between the large and small males or between first and second ejaculates. In this study, since we did not examine sperm quality, we cannot assert that sperm limitation occurred in female spiny king crab. The relationships between male size or male mating frequency and sperm quality must be clarified in future studies. However, it is certain that the male mating frequency and male size influenced the reproductive success of females.

Some females failed to mate with males larger than $120 \mathrm{~mm}$ CL as the male mating frequency increased, a tendency also observed in the largest males of the red king crab (Paul \& Paul 1990). Since no age determination method has been established for the spiny king crab, we did not estimate the age of crabs. Judging from individual sizes, however, we presume the large males were senescent. If so, a decline in reproductive potential due to aging is expected and may have led males to fail at mating. The reproductive potential of males in the spiny king crab shows tendencies similar to those of the red king crab (Paul \& Paul 1990).

The recovery rate of sperm available for mating was very slow. Although the number of sperm in the testis increased as the number of days after males became incapable of mating increased, the number of sperm stored in the vasa deferentia did not increase even $28 \mathrm{~d}$ after the males became depleted, which indicates that spermatophore production is costly for males. In large males of the blue crab Callinectes sapidus, exhausted sperm recovers completely between 9 and $20 \mathrm{~d}$ after mating (Kendall et al. 2001). As large blue crab males typically guard females for 2 to $5 \mathrm{~d}$ before mating (Jivoff 1995), large males that have mated may recover some sperm and their seminal fluid by the next mating (Kendall et al. 2001). In contrast, spiny king crab males may mate with females before they recover their sperm enough for full fertilization of her clutch, because the recovery rate of depleted sperm is very slow, which causes females to be prone to have a limited sperm supply. This characteristic of the spiny king crab males would be one factor that increases the intensity of sperm limitation for females, particularly in fished populations with a few available males compared with females, especially late in the reproductive season. This speculation is supported by the fact that the proportion of depleted males increased throughout the reproductive season. The decrease in male reproductive output with increasing male mating frequency and the low recovery rate of sperm available for mating may make a gradient in the number of sperm supplied to females within the reproductive season in the fished population; that is, a gradient of female reproductive success due to their timing of mating. Further work will attempt to verify whether sperm limitation restricts the reproductive rate of the fished spiny king crab population by investigating the relationship between the reproductive success of females and the females' timing of mating. Besides, we must also examine whether male size influences the recovery rate of the sperm reserves in the spiny king crab.

The present fishing regulations for this species, which only allow the harvesting of large males, will skew the sex ratio towards females and decrease the mean male size in the fished spiny king crab population. After the change in fishing regulations in 1991, the mean male size decreased and the sex ratio skewed sharply towards females. In addition, the number of males larger than $69.7 \mathrm{~mm}$ CL (i.e. minimum legal size limit) decreased markedly. Generally, the population structure of fished species is affected not only by anthropogenic factors such fishing but also by environmental factors such as temperature. A series of atmospheric and oceanographic changes occurred over the North Pacific in 1988-1989, known as a 'minor regime shift', and lasted for several years (Minobe 2000). However, in the Hamanaka area, there were no notable differences in either water temperature (1990: $4.5 \pm 1.4(\mathrm{SD}){ }^{\circ} \mathrm{C}, 1991: 4.8 \pm 1.5^{\circ} \mathrm{C}$ ) or in the relative density of seawater (1990: $1.0244 \pm 0.0013$ (SD) $\mathrm{g} \mathrm{ml}^{-1}$, 1991: $1.0245 \pm 0.0005(\mathrm{SD}) \mathrm{g} \mathrm{ml}^{-1}$ ) between reproductive seasons (April to May) in 1990 and 1991, when the population structure changed sharply. Therefore, the increased fishing pressure on larger males caused by the change in the fishing regulations appears to have changed the spiny king crab population structure.

The present fishing regulations may lead to overfishing and increase the potential for sperm limitation of Paralithodes brevipes. In such a fished population altered by sex- and size-selective fishing, the few males remaining in the fishing ground would likely mate often (e.g. Ennis et al. 1988, 1990, Sainte-Marie 1993). This speculation for this species is also supported by the fact that many males across the adult size range $(42.2 \%)$ depleted their sperm resources by the end of the reproductive season in late May. Judging from the male size distribution of the fished spiny king crab population and the scanty reproductive potential of males between 70 and $80 \mathrm{~mm} \mathrm{CL}$, most individuals participating in mating activity would be males between about 70 and $90 \mathrm{~mm} \mathrm{CL}$ in the fished spiny king crab population. In our laboratory experiment, males between 70 and $80 \mathrm{~mm}$ CL had low fertilization rates even at the first mating, which probably resulted from their low ability to pass sufficient sperm to fertilize a female's clutch or the low quality of their sperm. 
Males between 80 and $90 \mathrm{~mm}$ CL showed a marked decrease in the ejaculate size, in the percentage of spawning success of females, and in fertilization rate with increasing mating frequency, even before the male depleted its sperm resource. There were many depleted males especially between 80 and $90 \mathrm{~mm} \mathrm{CL}$ in the fished population. Therefore, the reproductive rate of the fished population would be restricted. In fact, female spiny king crabs without incubated eggs occupy a relatively high proportion of fished populations in eastern Hokkaido (Tsutsui 2000).

A notable tendency is that smaller males deplete their sperm reserves to a greater extent than larger males in fished populations just after the reproductive season. Despite the fact that larger males of the spiny king crab have a competitive advantage for females than smaller males (Wada et al. 1997), even small males had many matings before being depleted, indicating a decrease in competition for possession of receptive females among remaining males; that is, an excessive decrease in male density in fished populations. Decreases in male density reduce the frequency of female encounters with potential male mates (Gray \& Powell 1964, Powell et al. 1974, Ennis 1980, Smith \& Jamieson 1991), which would increase the probability that females fail to mate within the optimal duration after molting. Since spiny king crab females also have an optimal duration to mate and fertilize successfully after their molting (Sato et al. 2005), the reproductive success of a fished population with an excessive decrease in male density may also be restricted by such a female reproductive characteristic.

The present fisheries may deplete the spiny king crab resource in the near future. In the future, to estimate a decrease in reproductive rate of the fished spiny king crab population, we should investigate the number of matings by 1 male in a reproductive season, the number of females that participate in matings in fished populations, the reproductive success of females (percentage of spawning success and fertilization rate), and some aspects of reproductive characteristics of this species (e.g. female choice and female sexual receptive duration after molting). To maintain the resource of the spiny king crab, we should reconsider the present regulations, particularly the minimum legal size, and should establish effective resource management which is also applicable to other large crustacean species that have similar sex-selective fishing regulations, based on the reproductive potential of male size in each species.

Acknowledgements. We thank A. Nishiki for providing us with samples, facilities and valuable advice, and other members of the IAA, FRA, National Center for Stock Enhancement, Akkeshi Station, who kindly helped us with the experiments. We also thank the staff of the Hokkaido Kushiro
Fisheries Experimental Station for providing us with valuable data, the Akkeshi Marine Station, Aquatic Research Station, Field Science Center for Northern Biosphere, Hokkaido University for providing us with valuable data, anonymous referees for their constructive comments regarding this manuscript, J. R. Bower for improving the English text, and all members of the Laboratory of Marine Biodiversity, Graduate School of Fisheries Sciences, Hokkaido University, for their discussions. This work was made possible by the generous hospitality and cooperation of the fishermen and staff of Hamanaka Fishermen's Cooperative Association.

\section{LITERATURE CITED}

Abbe GR, Stagg C (1996) Trends in blue crab (Callinectes sapidus Rathbun) catches near Calvert Cliffs, Maryland, from 1968 to 1995 and their relationship to the Maryland commercial fishery. J Shellfish Res 15:751-758

Birkhead TR (1991) Sperm depletion in the Bemgalese finch, Lonchura atriata. Behav Ecol 2:267-275

Bissoondath CJ, Wiklund C (1996) Effects of male mating history and body size on ejaculate size and quality in two polyandrous butterflies, Pieris napi and Pieris rapae (Lepidoptera: Pieridae). Funct Ecol 10:457-464

Dewsbury DA (1982) Ejaculate cost and male choice. Am Nat 119:601-610

Ennis GP (1980) Size-maturity relationships and related observations in Newfoundland populations of the lobster (Homarus americanus). Can J Fish Aquat Sci 37:945-956

Ennis GP, Hooper RG, Taylor DM (1988) Functional maturity in small male snow crabs (Chionoecetes opilio). Can J Fish Aquat Sci 45:2106-2109

Ennis GP, Hooper RG, Taylor DM (1990) Changes in the composition of snow crab (Chionoecetes opilio) participating in the annual breeding migration in Bonne Bay, Newfoundland. Can J Fish Aquat Sci 47:2242-2249

Gage MJG, Cook PA (1994) Sperm size or numbers? Effects of nutritional stress on eupyrene and apyrene sperm production strategies in the moth Plodia interpunctella (Lepidoptera: Pyralidiae). Funct Ecol 8:594-599

Gray GW, Powell GC (1964) Sex ratios and distribution of spawning king crabs in Alitak Bay, Kodiak Is., Alaska (Decapoda, Anomura, Lithodidae). Crustaceana 10:303-309

Hankin DG, Butler TH, Wild PW, Xue QL (1997) Does intense fishing on males impair mating success of female Dungeness crab? Can J Fish Aquat Sci 54:655-669

Jivoff PR (1995) The role of mate guarding, male size, and male investment on individual reproductive success on the blue crab, Callinectes sapidus. PhD thesis, University of Maryland, College Park, MD

Jivoff PR (1997) Sexual competition among male blue crab, Callinectes sapidus. Biol Bull (Woods Hole) 193:368-380

Kendall MS, Wolcott DL, Wolcott TG, Hines AH (2001) Reproductive potential of individual male blue crabs, Callinecetes sapidus, in a fished population: depletion and recovery of sperm number and seminal fluid. Can J Fish Aquat Sci 58:1168-1177

Kendall MS, Wolcott DL, Wolcott TG, Hines AH (2002) Influence of male size and mating history on sperm content of ejaculates of the blue crab Callinectes sapidus. Mar Ecol Prog Ser 203:235-240

Kwei EA (1978) Size composition, growth and sexual maturity of Callinectes latimanus (Rathbun) in two Ghanaian lagoons. Zool J Linn Soc 64:151-175

Lawless JF (1982) Statistical models and methods for lifetime data. John Wiley, NewYork 
MacDiarmid AB, Butler MJ (1999) Sperm economy and limitation in spiny lobsters. Behav Ecol Sociobiol 46:1-24

Millikin MR, Williams AB (1980) Synopsis of biological data on the blue crab, Callinectes sapidus Rathbun. NOAA Tech Rep NMFS:1-39

Minobe S (2000) Spatio-temporal structure of the pentadecadal variability over the North Pacific. Prog Oceanogr 47:381-408

Miyake S (1982) Japanese Crustacean Decapods and Stomatopods in color, Vol I. Macrura, Anomura, and Stomatopoda. Hoikusya Publishing, Osaka (in Japanese)

Mori Y (1993) Investigation of spiny king crab Paralithodes brevipes resource. Sci Rep Hokkaido Kushiro Fish Exp Sta, p 199-203 (in Japanese)

Nakatsuru K, Kramer DL (1982) Is sperm cheap? Limited male fertility and female choice in the lemon tetra (Pisces, Characidae). Science 16:753-755

Paul AJ, Adams AE (1984) Breeding and fertile period for female Chionoecetes bairdi (Decapoda, Majidae). J Crustac Biol 4:589-594

Paul AJ, Paul JM (1992) Second clutch viability of Chionoecetes bairdi Rathbun (Decapoda: Majidae) inseminated only at the maturity molt. J Crustac Biol 12:438-441

Paul AJ, Paul JM (1997) Breeding success of large male red king crab Paralithodes camtschaticus with multiparous mates. J Shellfish Res 16:379-381

Paul JM, Paul AJ (1990) Reproductive success of sublegal size male red king crab (Paralithodes camtschatica) with access to multiple mates. Proc Int Symp King \& Tanner Crabs Nov. 1989, Anchorage, AK, p 37-50

Pitnick S, Markow TA (1994) Male gametic strategies: sperm size, testes size, and the allocation of ejaculate among successive mates by sperm-limited fly Drosophila pachea and its relatives. Am Nat 143:785-819

Powell GC, James KE, Hurd CL (1974) Ability of male king crab, Paralithodes camtschatica, to mate repeatedly, Kodiak, Alaska, 1973. Fish Bull US 72:171-179

Preston BT, Stevenson IR, Pemberton JM, Wilson K (2001) Dominant rams lose out by sperm depletion. Nature 409:681-682

Rondeau A, Sainte-Marie B (2001) Variable mate-guarding time and sperm allocation by male snow crab (Chionoecetes opilio) in response to sexual competition, and their impact on the mating success of females. Biol Bull (Woods Hole) 201: 204-217

Royer L, McNeil JM (1993) Male investment in the European corn borer, Ostrinia nubilalis (Lepidoptera Pyralidae) -

Editorial responsibility: Otto Kinne (Editor-in-Chief), Oldendorf/Luhe, Germany impact on female longevity and reproductive performance. Funct Ecol 7:209-215

Rutowski RL, Gilcrist GW, Terkanian B (1987) Female butterflies mated with recently mated males show reduced reproductive output. Behav Ecol Sociobiol 20:319-322

Sainte-Marie B (1993) Reproductive cycle and fecundity of primiparous and multiparous female snow crab, Chionoecetes opilio, in the northwest Gulf of Saint Lawrence. Can J Fish Aquat Sci 50:2147-2156

Sainte-Marie B, Hazel F (1992) Moulting and mating of snow crabs, Chionoecetes opilio (O. Fabricius), in shallow waters of the northwestern Gulf of Sainte Lawrence. Can J Fish Aquat Sci 49:1282-1293

Sapelkin AA, Fedoseev VY (1986) Spermatophore formation and accumulation of sexual products in male king crab. Biol Morya 12:34-38

Sato S, Abe Y (1941) Fecundity of the king crab, Paralithodes brevipes. Sci Rep Hokkaido Fish Exp Sta 81:244-246 (in Japanese)

Sato T, Ashidate M, Goshima S (2004) A new method to extract sperm from spermatophores of the male spiny king crab Paralithodes brevipes (Anomura: Lithodidae). Crustac Res 33:10-14

Sato T, Ashidate M, Goshima S (2005) Negative effects of delayed mating on the reproductive success of female spiny king crab, Paralithodes brevipes. J Crustac Biol 25:105-109

Smith BD, Jamieson GL (1991) Possible consequences of intensive fishing for males on the mating opportunities of Dungeness crabs. Trans Am Fish Soc 120:650-653

Svensson MGE, Marling E, Löfqvist J (1998) Mating behavior and reproductive potential in the turnip moth Agrotis segetum (Lepidoptera: Noctuidae). J Insect Behav 11:343-359

Tsutsui D (2000) Investigation of spiny king crab Paralithodes brevipes resource. Sci Rep Hokkaido Kushiro Fish Exp Sta, p 233-234 (in Japanese)

Wada S, Ashidate M, Goshima S (1997) Observations on the reproductive behavior of the spiny king crab Paralithodes brevipes (Anomura: Lithodidae). Crustac Res 26:56-61

Wada S, Ashidate M, Yoshino K, Sato T, Goshima S (2000) Effects of sex ratio on egg extrusion frequency and mating behavior of the spiny king crab Paralithodes brebipes (Decapoda: Lithodidae). J Crustac Biol 20:479-482

Waddy SL, Aiken DE (1986) Multiple fertilization and consecutive spawning in large American lobster, Homarus americanus. Can J Fish Aquat Sci 43:2291-2294

Submitted: March 15, 2004; Accepted: December 28, 2004

Proofs received from author(s): May 26, 2005 